\title{
Management of a necrosed bile duct by combination of a fully covered metal biliary stent and endoscopic ultrasound-guided gastrojejunostomy
}

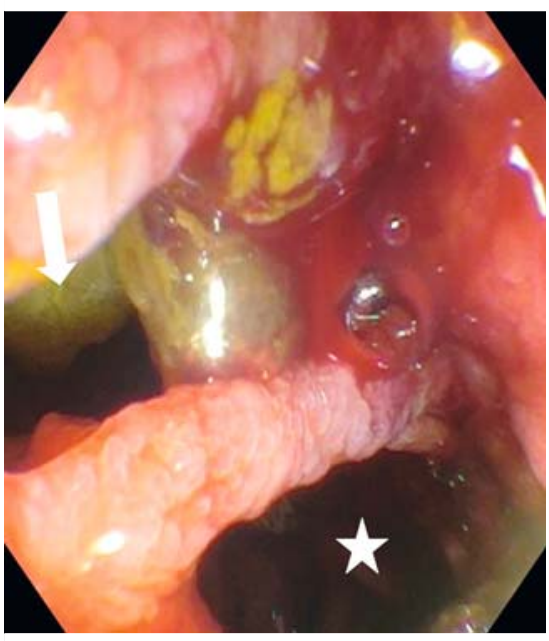

- Fig. 1 Necrotic cavity at second portion of duodenum with visible lateral wall of indwelling biliary stent (arrow); duodenal lumen is visible separately (star).

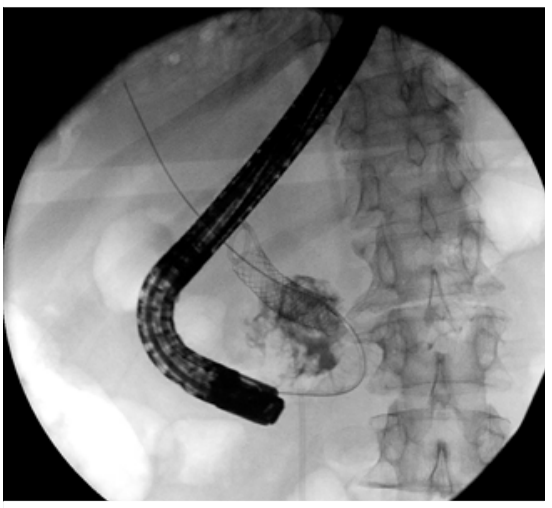

Fig. 2 Cholangiogram demonstrating contrast extravasation through the side holes of the indwelling uncovered metal biliary stent into a contained necrotic cavity.

Endoscopic ultrasound-guided gastrojejunostomy (EUS-GJ) is an emerging procedure in the management of gastric outlet obstruction [1-5]. One potential application of EUS-G] is to divert luminal contents away from a luminal defect in order to minimize infection and/or facilitate healing.

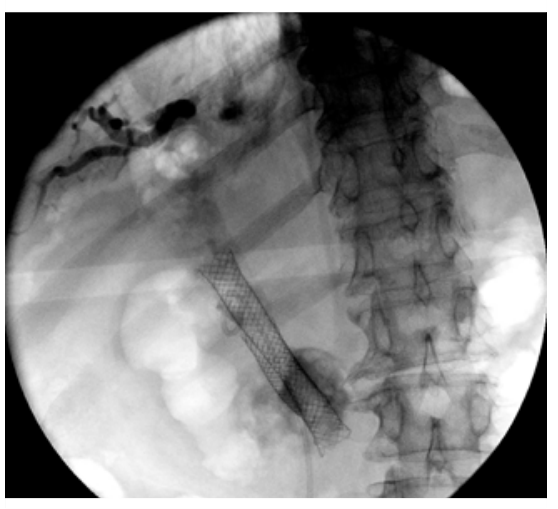

Fig. 3 Placement of a coaxial fully covered metal biliary stent.

The patient is a 71-year-old man with a history of pancreatic adenocarcinoma and uncovered metal biliary stent placement 16 months ago who was admitted with cholangitis and bacteremia (E. coli and Klebsiella) secondary to an occluded biliary stent.

Endoscopic retrograde cholangiopancreatography (ERCP) demonstrated tumor infiltration of the medial duodenal wall with an associated necrotic debrisfilled cavity ( $\triangleright$ Video 1 ). The lateral wall of the indwelling metal stent was clearly visible in the cavity, consistent with necrosis of the bile duct ( $\triangleright$ Fig. 1 ).

Cholangiogram demonstrated extravasation of contrast through the stent side holes into a contained cavity ( $>$ Fig. 2 ). To prevent further contamination of the biliary tree, a $10-\mathrm{mm} \times 60-\mathrm{mm}$ fully covered metal biliary stent (Wallflex; Boston Scientific, Marlborough, Massachusetts, USA) was placed within the uncovered stent (> Fig.3). Repeat cholangiogram confirmed no further extravasation.

To minimize the risk of further soiling of the necrotic cavity and bile duct, EUS-GJ was pursued with the goal of diverting luminal contents away from this area. Approximately 250 cc of a dilute methylene blue/saline/contrast solution was infused into the proximal jejunum. A loop

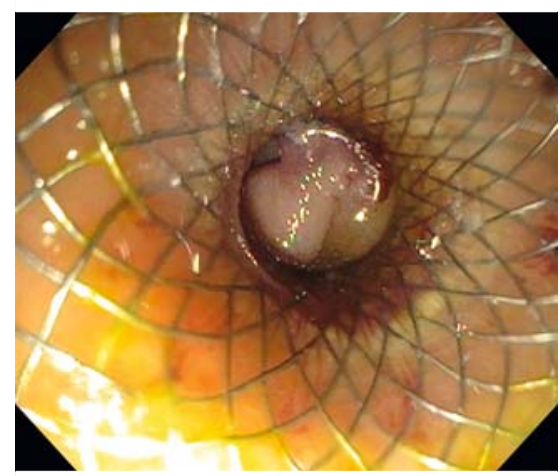

>Fig.4 Endoscopic ultrasound-guided gastrojejunostomy with a lumen-apposing metal stent.

of jejunum adjacent to the gastric wall was identified and a $15-\mathrm{mm} \times 10-\mathrm{mm}$ electrocautery-enhanced lumen-apposing metal stent (LAMS) (Hot Axios; Boston Scientific) was placed ( $\triangleright$ Fig.4).

The patient tolerated the procedure well and was started on a clear liquid diet that night. He was discharged home 2 days later. At 1 month follow-up, the patient was eating a full diet and was otherwise doing well.

This case demonstrates a novel use of endoscopic ultrasound-guided gastrojejunostomy to manage a gastrointestinal luminal defect. Other potential applications may include management of gastroduodenal fistulas, perforations, and post-operative leaks.

Endoscopy_UCTN_Code_CPL_1AK_2AD

\section{Competing interests}

Dr. DiMaio is a speaker and consultant for Boston Scientific and Covidien as well as a speaker for AbbVie. Dr. Kumta is a consultant for Olympus America, Boston Scientific, Apollo Endosurgery, and Gyrus ACMI. The other authors have no interests to declare. 


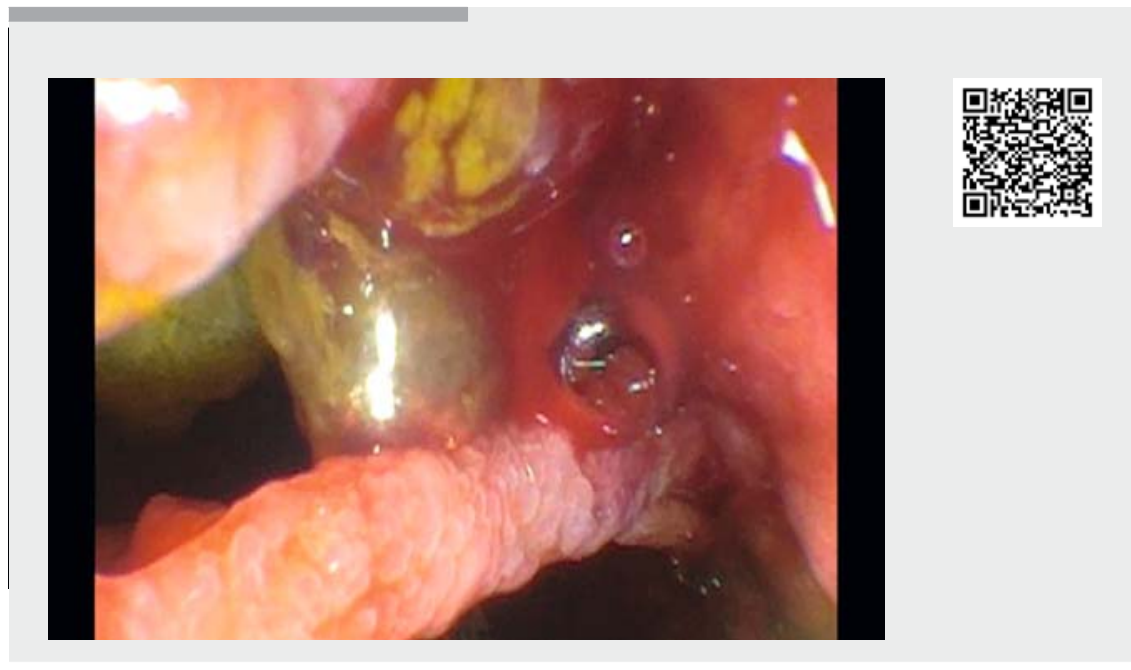

$\checkmark$ Video 1 Management of cholangitis from a necrotic bile duct with combined fully covered metal biliary stent and endoscopic ultrasound-guided gastrojejunostomy.

The authors

\section{Christopher J. DiMaio, Antonio R. Cheesman,} Satish Nagula, Nikhil A. Kumta

Dr. Henry D. Janowitz Division of

Gastroenterology, Icahn School of Medicine at

Mount Sinai, New York, NY

\section{Corresponding author}

\section{Christopher J. DiMaio, MD}

Dr. Henry D. Janowitz Division of

Gastroenterology, Icahn School of Medicine at Mount Sinai, One Gustave L. Levy Place, Box 1069, New York, NY 10029, USA

Fax: +1-212-241-2276

Christopher.DiMaio@mountsinai.org

\section{References}

[1] Tyberg A, Perez-Miranda M, Sanchez-Ocana $R$ et al. Endoscopic ultrasound-guided gastrojejunostomy with a lumen-apposing metal stent: a multicenter, international experience. Endosc Int Open 2016; 4: E276E281

[2] Chen YI, Itoi It, Baron TH et al. EUS-guided gastroenterostomy is comparable to enteral stenting with fewer re-interventions in malignant gastric outlet obstruction. Surg Endosc 2017; 31: 2946-2952

[3] Khashab MA, Bukhari M, Baron TH et al. International multicenter comparative trial of endoscopic ultrasonography-guided gastroenterostomy versus surgical gastrojejunostomy for the treatment of malignant gastric outlet obstruction. Endosc Int Open 2017; 5 : E275-E281
[4] Chen YI, James TW, Agarwal A et al. EUSguided gastroenterostomy in the management of benign gastric outlet obstruction. Endosc Int Open 2018; 6: E363-E368

[5] Iqbal U, Khara HS, Hu Y et al. EUS-guided gastroenterostomy for the management of gastric outlet obstruction: a systematic review and meta-analysis. Endoscopic Ultrasound 2020; 9: 16-23

\section{Bibliography}

Endoscopy 2021; 53: E172-E173

DOI 10.1055/a-1216-0374

ISSN 0013-726X

published online 20.8.2020

(C) 2020. Thieme. All rights reserved.

Georg Thieme Verlag KG, Rüdigerstraße 14, 70469 Stuttgart, Germany

\section{ENDOSCOPY E-VIDEOS}

https://eref.thieme.de/e-videos

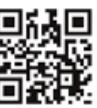

Endoscopy E-Videos is a free access online section, reporting on interesting cases and new techniques in gastroenterological endoscopy. All papers include a high quality video and all contributions are freely accessible online.

This section has its own submission website at https://mc.manuscriptcentral.com/e-videos 